\title{
CORRIGENDUM
}

\section{MiR-125a promotes paclitaxel sensitivity in cervical cancer through altering STAT3 expression}

Z Fan, H Cui, H Yu, Q Ji, L Kang, B Han, J Wang, Q Dong, Y Li, Z Yan, X Yan, X Zhang, Z Lin, Y Hu and S Jiao

Oncogenesis (2016) 5, e223; doi:10.1038/oncsis.2016.21; published online 9 May 2016

Correction to: Oncogene (2016) 5, e197; doi:10.1038/onc.2016.1; published online 15 February 2016

Following the online publication of this article, the authors noticed that $\mathrm{H} \mathrm{Yu}$ had been incorrectly referenced in the author list.
Please note that Z Fan, H Cui, H Yu and Q Ji contributed equally to this article.

This error has now been rectified.

The authors apologise for any inconvenience caused by this error. 